\title{
UMA NOVA ERA DAS PUBLICAÇÕES DA SBQ
}

A discussão sobre o impacto da internet na vida do ser humano tornou-se um clichê no final do século passado. Ela transformou o cotidiano das pessoas, seu modo de vida, seu trabalho e sua interação com o mundo. A atividade científica adotou essa revolução antes mesmo de sua popularização. A adoção da internet e suas ferramentas pela comunidade científica foi intuitiva e ao mesmo tempo avassaladora, sem tempo para considerações ou opções. Não há possibilidade de qualquer comparação do momento atual com tempos, nem tão remotos, nos quais as teses eram impressas em mimeógrafos, computadores stand-by eram do tamanho de uma geladeira, o Chemical Abstracts pesava dois quilos por volume e as publicações, recentes ou antigas, eram acessadas, quando disponíveis, na seção "periódicos" da biblioteca. O cientista do século XXI gera uma cópia pdf de sua tese que é disponibilizada, via web, em celulares que cabem no bolso, sua pesquisa bibliográfica cobrindo praticamente $100 \%$ do acervo de artigos já publicados é produzida em frações de segundo a partir de diversos bancos de dados de acesso público, e o acesso aos artigos originais... ora, temos o portal Periódicos CAPES, o que mais queremos?

O sistema editorial foi o que mais participou - talvez de forma compulsória - desta reforma/revolução. $\mathrm{O}$ acesso de informações a partir de publicações de diversos tipos é agora feito em tempo real diretamente de seu tablet ou celular, de qualquer lugar, sujeito a ferramentas instantâneas de busca que facilitam o acesso orientado. Jornais e revistas tradicionais estão na web e suas versões impressas estão deixando de existir. Em notícia recente (27/09/2013) o "Lloyd's List", considerado o jornal em circulação mais antigo do mundo, anunciou que deixará de enviar aos seus meros 25 últimos assinantes sua versão impressa. O jornal, de 279 anos de edições impressas, continuará sua trajetória através de acesso on-line. Outras publicações de grande porte anunciaram também o fim de suas versões impressas, como a revista Newsweek.

A editoração científica não ficou atrás. $\mathrm{O}$ acesso on-line é obrigatório a toda e qualquer publicação de respeito, e o open access, acesso gratuito, é a grande discussão do momento. Quanto a isso, a SBQ é pioneira: suas publicações passaram a ser open access desde a implementação de suas versões on-line. Mais do que isso, tem mantido uma rígida política de manutenção do open access, a despeito de persistentes investidas de grandes editoras internacionais para assumir as operações de editoração tanto do JBCS quanto da Química Nova.

Durante quase toda a sua existência a QN impressa foi enviada "gratuitamente" aos associados em dia com a anuidade da SBQ, a um alto custo. Esse custo sempre foi dividido entre a tesouraria da SBQ e as agências de fomento (essencialmente, CNPq e FAPESP). Com a popularização de sua versão on-line, o interesse pela versão impressa foi nitidamente caindo. Em 2009, a Diretoria e Conselho decidiu por separar da anuidade um valor - bastante simbólico - referente à assinatura da versão impressa. $\mathrm{O}$ valor da assinatura cobria, com alguma dificuldade, o valor de despesas de frete, enquanto as despesas com impressão ficavam por conta de projetos pagos pelas agências de fomento citadas. No primeiro ano, o número de assinantes - agora voluntários - caiu de 3400 a 2200, quando passamos a imprimir $65 \%$ do volume do ano anterior. Nos anos seguintes esse número continuou caindo para 1900 em 2010, 600 em 2012 e 330 assinantes atuais.

No JBCS a história não foi diferente. O número de assinaturas caiu de cerca de 200 em 2009 para menos de 80 em 2013. Outro número importante é que os custos de impressão de 150-200 exemplares da revista são superiores a $\mathrm{R} \$ 120$ mil por ano, correspondendo a mais da metade do custo total de produção da revista e superior à manutenção do escritório e funcionários da SBQ dedicados ao JBCS.

Já em 2012, os editores de JBCS e QN estavam convictos que ambos periódicos estavam destinados a reduzir bastante o número de revistas de suas edições impressas. Um minucioso estudo foi feito e submetido à Diretoria e Conselho para análise, com a proposta de suspensão imediata de qualquer subsídio às versões impressas para assinantes, mantendo-se apenas as assinaturas institucionais (bibliotecas, institutos, etc.). A proposta inclui ainda a substituição da impressão em larga escala (em máquinas offset) por impressão sob demanda. Na prática, isso deverá trazer o preço das assinaturas a valores praticados por editorias comerciais. Acreditamos que a implementação desta política deverá resultar em uma diminuição drástica do número de assinaturas, mantendo a opção de sua aquisição aos leitores renitentes de papel. Junto com isso haverá, também, uma importante diminuição dos gastos, em consonância com os anseios das agências que, já preveem, não poderão continuar neste nível de financiamento do crescente mercado editorial científico brasileiro. Certamente estes recursos economizados poderão ser utilizados em outras necessidades prementes das publicações e da própria SBQ.

A reunião da Diretoria e Conselho da SBQ de agosto de 2013 aprovou, por unanimidade, a aplicação deste plano, que será implementado a partir de janeiro de 2014. A qualidade de sua diagramação, assim como de sua impressão, será mantida. Também será garantida a manutenção do ISBN de sua versão impressa. O assinante que assim o desejar poderá adquirir sua versão impressa, com base em assinaturas anuais, porém sem o subsídio, que em parte era coberto por todos os associados da SBQ.

Em tempos de Web 2.0, as mudanças de paradigmas estão voltadas para a geração de uma "inteligência coletiva”, libertária e democrática, de acesso irrestrito a todos, sendo processada em uma "nuvem" que já não possui um sentido de hardware stricto-sensu. Nas editorias do JBCS e QN, a busca por essa "inteligência coletiva" continuará por meio da busca incessante da excelência e da comunicação aberta e franca com a comunidade química nacional.

Editores do JBCS e Química Nova 


\section{química nova}

Química Nova publica artigos com resultados originais de pesquisa, trabalhos de revisão, divulgação de novos métodos ou técnicas, educação e assuntos gerais, em português, inglês e espanhol. Os artigos submetidos à revista são avaliados por consultores ad hoc (do Brasil e do exterior) especialistas na área envolvida e que, eventualmente, podem pertencer ao Conselho Editorial. A edição de Química Nova está a cargo de um corpo editorial e suas linhas gerais e planejamento de longo prazo estão sob responsabilidade dos Editores e do Conselho Editorial. Química Nova publica 10 fascículos por ano.

A versão on line está disponível em:

http://quimicanova.sbq.org.br/quimicanova.htm

Indexação: Chemical Abstracts, ISI e SciELO.

\section{Editores}

Luiz Henrique Catalani (USP)

Susana I. C. de Torresi (USP)

Vera L. Pardini (USP)

\section{Editores Associados}

Aldo J. G. Zarbin (UFPR)

Débora de A. Azevedo (UFRJ)

Jorge M. David (UFBA)

Marco T. Grassi (UFPR)

Renato S. Freire (USP)

Rochel M. Lago (UFMG)

Gerente Editorial

Ursula Brocksom

\author{
Conselho Editorial \\ Damià Barceló (Espanha) \\ Denise F. S. Petri (IQ/USP) \\ Ernesto Calvo (Argentina) \\ Glaura G. Silva (UFMG) \\ Hector Mansilla (Chile) \\ Heloise O. Pastore (UNICAMP) \\ Jorge Calderon (Colômbia) \\ José A. da S. Cavaleiro (Portugal) \\ Julio C. Afonso (UFRJ) \\ Luiz Lopes (UFC) \\ Marcus M. Sá (UFSC) \\ Nelson H. Morgon (UNICAMP) \\ Roberto Faria (UFRJ) \\ Salete L. Queiroz (IQSC/USP) \\ Silvio do D. Cunha (UFBA)
}

\section{SOCIEDADE BRASILEIRA DE QUÍMICA}

\section{Diretoria}

Presidente: Vitor Francisco Ferreira (UFF)

Presidente Sucessor: Adriano D. Andricopulo (IFSC-USP)

Vice-Presidente: Claudia Moraes de Rezende (UFRJ)

Secretário Geral: Aldo José Gorgatti Zarbin (UFPR)

Secretário Adjunto: Luiz Fernando da Silva Jr. (IQUSP)

Tesoureira: Rossimiriam Pereira de Freitas (UFMG)

Tesoureiro Adjunto: Carlos Alberto Manssour Fraga (UFRJ)

Diretora Executiva: Dirce Maria F. Campos

\section{Conselho Consultivo}

César Zucco (UFSC)

Fernando Galembeck (UNICAMP)

Jailson Bittencourt de Andrade (UFBA)

Luiz Henrique Catalani (IQUSP)

Marília Fonseca Goulart (UFAL)

Paulo Cezar Vieira (UFSCar)

Vanderlan da Silva Bolzani (UNESP)

\section{Conselho Fiscal}

Titulares

Norberto Peporine Lopes (FCFRP-USP)

Sérgio de Paula Machado (UFRJ)

Roberto de Barros Faria (UFRJ)

\section{Suplentes}

Ricardo Bicca de Alencastro (UFRJ)

Fernando Antonio Santos Coelho (UNICAMP)

\section{Copyright () 2013 Sociedade Brasileira de Química}

Para publicação, requer-se que os manuscritos submetidos a esta revista não tenham sido publicados anteriormente e não sejam submetidos ou publicados simultaneamente em outro periódico. Ao submeter o manuscrito, os autores concordam que o copyright de seu artigo seja transferido à Sociedade Brasileira de Química (SBQ), se e quando o artigo for aceito para publicação.

O copyright abrange direitos exclusivos de reprodução e distribuição dos artigos, inclusive separatas, reproduções fotográficas, microfilmes ou quaisquer outras reproduções de natureza similar, inclusive traduções. Nenhuma parte desta publicação pode ser reproduzida, armazenada em bancos de dados ou transmitida sob qualquer forma ou meio, seja eletrônico, eletrostático, mecânico, por fotocopiagem, gravação, mídia magnética ou algum outro modo, sem permissão por escrito da detentora do copyright.

Embora todo esforço seja feito pela SBQ, Editores e Conselho Editorial para garantir que nenhum dado, opinião ou afirmativa errada ou enganosa apareçam nesta revista, deixa-se claro que o conteúdo dos artigos e propagandas aqui publicados são de responsabilidade, única e exclusiva, dos respectivos autores e anunciantes envolvidos. Consequentemente, a SBQ, o Conselho Editorial, os Editores e respectivos funcionários, diretores e agentes isentam-se, totalmente, de qualquer responsabilidade pelas conseqüências de quaisquer tais dados, opiniões ou afirmativas erradas ou enganosas.

Photocopying information for users in the USA. The Item-Fee Code for this publication indicates that authorization to photocopy items for internal or personal use is granted by the copyright holder for libraries and other users registered with the Copyright Clearance Center (CCC) Transactional Reporting Service, provided the stated fee for copying beyond that permitted by Section 107 and 108 of the United States Copyright Law is paid. The appropriate remittance of $\$ 6,00$ per copy per article is paid directly to the Copyright Clearance Center Inc., 222 Rosewood Drive, Danvers, MA 01923, U.S.A.

Permission for other use. The copyright owner's consent does not extend to copying for general distribution, for promotion, for creating new works, or for resale. Specific written permission must be obtained from the Publisher for such copying.

The Item-Fee Code for this publication is 0100-4042\$6.00+0.00

\section{Tiragem: 400 exemplares Circulação: Novembro/2013}

Editoração Eletrônica: Hermano - Tel.: (11) 5571-8937

Capa: Ana Paula Toscano - Tel.: (11) 9274-7523

Impressão: Margraf Editora e Indústria Gráfica - Tel.: (11) 4689-7100
Pedido de assinatura e distribuição

Secretaria da SBQ

Instituto de Química - USP

Av. Prof. Lineu Prestes, 748

Bloco 3 - superior

Tel.: (011) 3032-2299/Fax: (011) 3814-3602

E-mail: sbqsp@sbq.org.br

Apoio: 